\title{
Nocturnal Intermittent Hypoxia and Metabolic Syndrome; the Effect of being Overweight: the CIRCS Study
}

\author{
Isao Muraki ${ }^{1,2}$, Takeshi Tanigawa ${ }^{3}$, Kazumasa Yamagishi ${ }^{4}$, Susumu Sakurai ${ }^{3}$, Tetsuya Ohira ${ }^{1}$, \\ Hironori Imano², Masahiko Kiyama², Akihiko Kitamura², Shinichi Sato ${ }^{2,5}$, Takashi Shimamoto², \\ Masamitsu Konishi ${ }^{2}$, and Hiroyasu Iso ${ }^{1}$, for the CIRCS Investigators
}

${ }^{1}$ Public Health, Department of Social and Environmental Medicine, Osaka University Graduate School of Medicine, Suita, Japan

${ }^{2}$ Osaka Medical Center for Health Science and Promotion, Osaka, Japan

${ }^{3}$ Department of Public Health, Doctoral Program in Social Medicine, Graduate School of Medicine, Ehime University, Toon, Japan

${ }^{4}$ Department of Public Health Medicine, Graduate School of Comprehensive Human Sciences, and Institute of Community

Medicine, University of Tsukuba, Tsukuba, Japan

${ }^{5}$ Chiba Prefectural Institute of Public Health, Chiba, Japan

\begin{abstract}
Aim: We investigated whether nocturnal intermittent hypoxia, a surrogate marker for obstructive sleep apnea, is associated with metabolic syndrome and its components among Japanese.

Methods: We examined 1,710 male and 2,896 female community-dwelling Japanese aged 40 to 69, who participated in annual cardiovascular examinations and investigations of sleep. Nocturnal intermittent hypoxia was estimated based on a 3\% oxygen desaturation index measured with pulse-oximetry during sleep. No, mild and moderate-to-severe nocturnal intermittent hypoxia were defined by $<5,5$ to $<15$ and $\geq 15$ events/hour, respectively. Metabolic syndrome was defined by modified criteria of the Adult Treatment Panel III guidelines.

Results: Compared with no nocturnal intermittent hypoxia, the multivariable odds ratio of metabolic syndrome was 1.9 (95\% confidence interval: $1.6-2.4)$ for mild and $3.2(2.2-4.7)$ for moderate-tosevere nocturnal intermittent hypoxia among men; 2.6 (2.1-3.4) and 5.8 (3.4-9.8) among women, respectively. When stratified by overweight status (body mass index $\geq 25 \mathrm{~kg} / \mathrm{m}^{2}$ ), the multivariable odds ratio of two or more metabolic risk factors (other than overweight) associated with moderateto-severe nocturnal intermittent hypoxia was 1.9 (1.2-3.1) among non-overweight subjects and 1.4 (0.9-2.1) among overweight subjects $(p$ for interaction $=0.002)$.

Conclusions: Nocturnal intermittent hypoxia was associated with the accumulation of metabolic risk factors, especially among non-overweight individuals.
\end{abstract}

J Atheroscler Thromb, 2010; 17:369-377.

Key words; Metabolic syndrome, Intermittent hypoxia, Sleep-disordered breathing, Overweight, Cross-sectional study

\section{Introduction}

Obstructive sleep apnea (OSA) is characterized by repetitive episodes of upper airway obstruction

Address for correspondence: Hiroyasu Iso, Public Health, Department of Social and Environmental Medicine, Osaka University Graduate School of Medicine, 2-2 Yamadaoka,

Suita, Osaka 565-0871, Japan

E-mail: iso@pbhel.med.osaka-u.ac.jp

Received: July 20, 2009

Accepted for publication: October 6, 2009 during sleep, which cause enhanced sympathetic activity, elevated intrathoracic pressure, increased cytokine levels, increased oxidative stress and sleep deprivation ${ }^{1)}$. OSA is associated with hypertension, dyslipidemia and glucose abnormality, independent of traditional confounding factors (e.g. age, sex and body mass index $(\mathrm{BMI}))^{2)}$. In addition, prospective studies have shown that OSA increases the risk of cardiovascular disease, independently of traditional confounding factors ${ }^{3)}$. Therefore, OSA has been noted as a new cardiovascular risk factor. 
Metabolic syndrome (MetS) reflects high cardiovascular risk conditions ${ }^{4-6)}$. The prevalence of MetS defined by the Adult Treatment Panel III guidelines of the National Cholesterol Education Program (NCEP/ ATPIII) was 2-fold higher among patients with an apnea-hypopnea index (AHI) $\geq 5$ than among those with $\mathrm{AHI}<5^{7,8)}, 2$ - to 4 -fold higher among those with $\mathrm{AHI} \geq 15$ than among those with $\mathrm{AHI}<15^{8,9)}$, and 9-fold higher among those with AHI $\geq 15$ and OSA-related symptoms (e.g. excessive daytime sleepiness) than among those without either ${ }^{10)}$. Vgontzas and colleagues suggested that MetS manifests as OSA, because of the association of MetS with increased oxidative stress, insulin resistance and increased levels of cytokines, which are also associated with OSA ${ }^{11,12)}$. However, since most previous studies recruited mainly obese or overweight subjects (body mass index, BMI; $\left.25.9-38.4 \mathrm{~kg} / \mathrm{m}^{2}\right)^{7-11)}$, and both OSA and MetS were strongly associated with BMI, prior findings may not be applicable to non-overweight populations.

To examine whether these associations were extrapolated in a lean population, we examined the association between nocturnal intermittent hypoxia and MetS among community-dwelling Japanese, which consisted mainly of non-overweight subjects.

\section{Methods}

The Circulatory Risk in Communities Study (CIRCS) is a prospective community-based study that has been launched to prevent stroke in five communities across Japan since 1963, described in detail elsewhere $^{6,13,14)}$. Annual cardiovascular risk surveys and monitoring of cardiovascular events are systematically conducted by a research team of the Osaka Medical Center for Health Science and Promotion, the Osaka University and the University of Tsukuba. An investigation of sleep as part of the annual cardiovascular surveys was started in three communities (Ikawa; a northeast rural community, Yao; a mid-west suburban community, and Kyowa; a mid-east rural community) in $2000^{15}$. The study protocol was approved by the Institutional Review Board of the Osaka Medical Center for Health Science and Promotion, Osaka University and the University of Tsukuba.

\section{Subjects}

The participants in the 2001 to 2005 annual cardiovascular surveys aged 40 to 69 years were recruited for the present investigation. The numbers of participants were 448 men and 853 women from Yao (recruitment rate among the cardiovascular survey participants $=95 \%$ for men and $77 \%$ for women), 397 men and 571 women from Ikawa (93\% and 88\%), and 917 men and 1,507 women from Kyowa $(89 \%$ and $87 \%$ ). No subject had a history of OSA diagnosed by a physician. Subjects who had a history of stroke $(n=55)$ or a history of heart disease $(n=33)$ were excluded. A total of 1,710 men and 2,896 women were enrolled in the present study. For each subject, a physician and trained staff explained the protocol in detail, and obtained informed consent.

\section{Measurement of Metabolic Risk Factors and Con- founding Variables}

Height in stocking feet and weight in light clothing were measured and BMI was calculated as weight $(\mathrm{kg})$ divided by the square of height $(\mathrm{m})$. Systolic and diastolic blood pressures (SBP and DBP) were measured by physicians using a standard mercury sphygmomanometer on the right arm while the subject was quietly seated after at least 5 min of rest.

For the measurement of serum lipids and glucose, venous blood was drawn from seated participants into a plain, siliconized glass tube and serum was separated within $30 \mathrm{~min}$. The serum sample was transported on dry ice to the Osaka Medical Center for Health Science and Promotion, and stored at $-70^{\circ} \mathrm{C}$ prior to analysis. Serum total cholesterol, HDL-cholesterol, triglyceride and glucose levels were measured using enzymatic methods for lipids and the hexokinase method for glucose with an automatic analyzer (AU2700, Olympus Co., Tokyo, Japan) at the Osaka Medical Center for Health Science and Promotion, whose laboratory is an international member of the US National Cholesterol Reference Method Laboratory Network ${ }^{16)}$.

We measured several potential confounders that might also contribute to or aggravate OSA ${ }^{2}$. Interviews were conducted to determine alcohol intake per day, number of cigarettes smoked per day, time since last meal, use of antihypertensive and diabetes medication, and for women, menopausal status. An interviewer assessed normal weekly alcohol intake which was converted to grams of ethanol per day. Persons who smoked $\geq 1$ cigarette/day were defined as current smokers. The distribution of time since the last meal did not differ between men and women; $<2$ hours $(8 \%$ for men, $5 \%$ for women), 2 hours $(9 \%, 7 \%), 3-7$ hours $(35 \%, 30 \%)$ and $\geq 8$ hours $(52 \%, 53 \%)$.

A modified definition of NCEP/ATPII ${ }^{17)}$ was used to categorize subjects according to metabolic risk factors. Since waist circumference was not available in the present study, BMI was used for the assessment of obesity. The Asian criterion of obesity is a BMI $\geq 25.0$ $\mathrm{kg} / \mathrm{m}^{2}$, or waist circumference $\geq 80 \mathrm{~cm}$ for women and 
$\geq 90 \mathrm{~cm}$ for $\mathrm{men}^{18)}$. MetS was defined as three or more of the following metabolic risk factors: 1) BMI $\geq 25.0 \mathrm{~kg} / \mathrm{m}^{2}$, 2) fasting plasma glucose concentration $\geq 110 \mathrm{mg} / \mathrm{dL}(6.11 \mathrm{mmol} / \mathrm{L})$ or non-fasting glucose concentration $\geq 140 \mathrm{mg} / \mathrm{dL}(7.77 \mathrm{mmol} / \mathrm{L})$ or on medication, 3) SBP $\geq 130 \mathrm{mmHg}$ or $\mathrm{DBP} \geq 85 \mathrm{mmHg}$ or on medication, 4) HDL-cholesterol concentration $<40 \mathrm{mg} / \mathrm{dL}(1.03 \mathrm{mmol} / \mathrm{L})$ for men and $<50 \mathrm{mg} / \mathrm{dL}$ $(1.29 \mathrm{mmol} / \mathrm{L})$ for women, and 5) fasting or nonfasting triglyceride concentration $\geq 150 \mathrm{mg} / \mathrm{dL}$ (1.69 $\mathrm{mmol} / \mathrm{L})$. The presence of $\geq 2$ metabolic risk factors was also defined as two or more metabolic risk factors other than overweight. We previously reported that MetS defined by these criteria was associated with incident ischemic stroke and heart disease ${ }^{6)}$.

\section{Assessment of Nocturnal Intermittent Hypoxia}

Nocturnal intermittent hypoxia was measured by Pulse-oximetry during one night's sleep using a pulseoximeter (PULSOX-3Si, Minolta Co., Osaka, Japan) at the participants' own home ${ }^{15)}$. The sensor probe was fitted to the fourth or fifth finger with tape. The device stores values of peripheral blood oxygen saturation by performing a moving average for the last 5 seconds, updated every second; this sampling time was short enough to avoid underestimation of oxygen desaturation ${ }^{19)}$. Data were downloaded to a personal computer via an interface (PULSOX IF-3, Minolta) and analyzed by proprietary software (DS-3 ver. 2.0a, Minolta). Because the measurement time of pulseoximetry is often longer than the true total sleep time, we used a single night's sleep log to exclude waking time from the analysis to minimize the potential for overestimating total sleep time. We used oxygen desaturation of $3 \%$ or more per hour of the adjusted measurement time (the 3\% oxygen desaturation index, $3 \% \mathrm{ODI}$ ) as the indicator for nocturnal intermittent hypoxia. The severity of nocturnal intermittent hypoxia was defined by the 3\%ODI level as 5 or 15 events per hour, corresponding to mild or moderateto-severe nocturnal intermittent hypoxia, respectively.

The validity of pulse-oximetry using synchronous overnight recordings of both PULSOX-3Si and standard polysomnography (PSG) was confirmed previously among 256 consecutive patients in a sleep-disordered breathing center (mean body mass index, 26.8 $\mathrm{kg} / \mathrm{m}^{2}$ ). The sensitivity and specificity were $80 \%$ and 95\%, respectively, for detecting an apnea-hypopnea index (AHI) of $\geq 5$ by PSG using a cut-off threshold of $3 \% \mathrm{ODI}=5$. Similarly, the sensitivity and specificity for detecting AHI of $\geq 20$ by PSG using a cut-off threshold of $3 \% \mathrm{ODI}=15$ were $85 \%$ and $100 \%$, respectively ${ }^{20)}$. To examine the reproducibility, pulse-oxime- try was conducted for two nights among 61 men in the present study. The median values of 3\%ODI were 5.4 on the first night and 4.8 on the second night ( $p$ for difference $=0.95$, Wilcoxon's signed-rank test). Spearman's rank correlation coefficient was $0.81(p<$ 0.001).

\section{Statistical Analysis}

Age and multivariable-adjusted mean values and prevalence of cardiovascular characteristics were calculated and tested by analysis of covariance according to $3 \%$ ODI. We used the logistic regression analysis to evaluate age- and multivariable-adjusted Odds ratios (ORs) of MetS according to 3\%ODI. A trend test was performed with a regression model for mean values, and a logistic regression model for propotion and odds ratios, using median values of 3\%ODI as representative of nocturnal intermittent hypoxia severity. The interactions of $3 \% \mathrm{ODI}$ with sex, overweight and BMI in relation to MetS and its components were tested using cross-product terms of these variables in the logistic regression model. We included age (year), sex, smoking status (nonsmoker and current smoker), current ethanol intake $(\mathrm{g} /$ day $)$, time since last meal $(<2,2$, 3-7 and $\geq 8$ hours) and for women, menopausal status (pre- and post-menopause), into the multivariable models. All analyses were conducted using the SAS statistical package, version 9.13 (SAS Institute Inc., Cary, NC). All $p$-values for statistical tests were twotailed and $p<0.10$ to 0.05 and $p<0.05$ was regarded as borderline significance and statistical significance, respectively.

\section{Results}

The age-adjusted prevalence of mild and moderate-to-severe nocturnal intermittent hypoxia essentially did not differ among these three communities; the prevalence was 29 to $35 \%$ for mild and 8 to $9 \%$ for moderate-to-severe nocturnal intermittent hypoxia among men, and 15 to $17 \%$ for mild and 2 to $3 \%$ for moderate-to-severe nocturnal intermittent hypoxia among women.

Sex-specific age-adjusted distributions of cardiovascular risk factors according to 3\%ODI are shown in Table 1. Mean values of age, BMI, SBP, DBP, serum glucose, triglyceride, and the proportion of antihypertensive medication use were higher, and mean values of HDL-cholesterol were lower, with increased $3 \%$ ODI among both sexes. Current ethanol intake and currently smoking were positively associated with $3 \%$ ODI among men. Mean values of serum total cholesterol were positively associated with $3 \% \mathrm{ODI}$ among 
Table 1. Sex-specific age-adjusted mean values (standard error) and prevalence of cardiovascular risk factors according to a $3 \%$ oxygen desaturation index

\begin{tabular}{|c|c|c|c|c|c|c|c|c|}
\hline & \multicolumn{4}{|c|}{ Men } & \multicolumn{4}{|c|}{ Women } \\
\hline & 0 to $<5$ & 5 to $<15$ & $\geq 15$ & $\begin{array}{l}p \text { for } \\
\text { trend }\end{array}$ & 0 to $<5$ & 5 to $<15$ & $\geq 15$ & $\begin{array}{l}p \text { for } \\
\text { trend }\end{array}$ \\
\hline No. & 1,031 & 527 & 152 & & 2,358 & 473 & 65 & \\
\hline Age, year & $57.5(0.2)$ & $58.4(0.3)$ & $59.6(0.6)$ & $<0.001$ & $55.8(0.2)$ & $59.5(0.4)$ & $60.7(1.0)$ & $<0.001$ \\
\hline Body mass index, $\mathrm{kg} / \mathrm{m}^{2}$ & $23.2(0.1)$ & $25.0(0.1)$ & $26.4(0.2)$ & $<0.001$ & $22.9(0.1)$ & $25.0(0.1)$ & $26.9(0.4)$ & $<0.001$ \\
\hline Current smoker, $\%$ & 46 & 40 & 36 & $<0.001$ & 5 & 4 & 2 & 0.15 \\
\hline Systolic blood pressure, $\mathrm{mmHg}$ & $130(0)$ & $133(1)$ & $137(1)$ & $<0.001$ & $125(0)$ & $127(1)$ & $135(2)$ & $<0.001$ \\
\hline Diastolic blood pressure, $\mathrm{mmHg}$ & $81(0)$ & $83(0)$ & $85(1)$ & $<0.001$ & $76(0)$ & $77(0)$ & $81(1)$ & $<0.001$ \\
\hline Serum blood glucose, mg/dL & $108.0(1.0)$ & $107.3(1.4)$ & $113.9(2.6)$ & 0.08 & $99.6(0.4)$ & $101.1(0.9)$ & $106.2(2.4)$ & 0.002 \\
\hline Serum total cholesterol, $\mathrm{mg} / \mathrm{dL}$ & $201.9(1.1)$ & $209.1(1.5)$ & $213.6(2.7)$ & $<0.001$ & $218.0(0.7)$ & $216.5(0.9)$ & $211.5(4.4)$ & 0.11 \\
\hline Use of diabetic medication, $\%$ & 5 & 4 & 6 & 0.95 & 2 & 4 & 2 & 0.03 \\
\hline
\end{tabular}

men, but inversely associated among women.

Table 2 shows the age- and multivariable-adjusted ORs of MetS and its components according to the severity of nocturnal intermittent hypoxia. Overweight, high blood pressure, a low HDL-cholesterol level and a high triglyceride level were positively associated with the severity of nocturnal intermittent hypoxia after adjustments for the confounding factors among both sexes. Glucose abnormality was associated with moderate-to-severe nocturnal intermittent hypoxia among men, but not among women. After further adjustment for BMI, the association of nocturnal intermittent hypoxia with each of these metabolic risk factors was weakened except for glucose abnormality. The age-adjusted prevalence of MetS was 2-fold and 4-fold higher for mild and moderate-tosevere nocturnal intermittent hypoxia, respectively among men, and 3-fold and 5-fold higher for mild and moderate-to-severe nocturnal intermittent hypoxia, respectively among women. After adjustments for the confounding factors, these associations did not change materially. The interaction of mild and moderate-tosevere nocturnal intermittent hypoxia with sex in relation to Met $S$ was statistically significant ( $p$ for interaction $=0.03$ for mild and 0.04 for moderate-to-severe nocturnal intermittent hypoxia).

Since the impact of being overweight on both nocturnal intermittent hypoxia and metabolic risk factors seemed to be large, we further examined associations between nocturnal intermittent hypoxia and metabolic risk factors stratified by overweight status (Table 3). The associations did not vary with the presence and absence of this factor although they tended to be stronger for high blood pressure and high triglyceride among overweight individuals. After further adjustment for BMI, the associations for high blood pressure and high triglyceride were weakened, but remained statistically significant among non-overweight subjects. The interaction between nocturnal intermittent hypoxia and BMI in relation to high blood pressure, a high triglyceride level, and the presence of 2 or more metabolic risk factors was statistically significant or borderline significant $(p$ for interaction $=0.006$ for high blood pressure, 0.08 for high triglyceride and 0.002 for the presence of $2 \geq$ metabolic risk factors).

\section{Discussion}

Nocturnal intermittent hypoxia was positively associated with MetS and its components among both men and women. The prevalence of MetS associated with nocturnal intermittent hypoxia was 2 to 3 -fold higher for persons with a ODI of 5 to $<15$ and 4 to 5-fold higher for persons with an ODI of $\geq 15$ compared with those with an ODI of $<5$. The magnitude of these associations was similar to those in previous studies of American and Chinese ${ }^{7-9)}$. As for the components of MetS, previous studies reported that nocturnal intermittent hypoxia was associated with 
Table 2. Sex-specific age- and multivariable-adjusted odds ratios (95\% confidence intervals) of metabolic risk factors and MetS according to the $3 \%$ oxygen desaturation index

\begin{tabular}{|c|c|c|c|c|c|c|c|c|}
\hline & \multirow{2}{*}{\multicolumn{3}{|c|}{$\begin{array}{c}\text { Men } \\
3 \% \mathrm{ODI} \\
\end{array}$}} & \multirow{2}{*}{\multicolumn{3}{|c|}{$\begin{array}{l}\text { Women } \\
3 \% \mathrm{ODI}\end{array}$}} & \multicolumn{2}{|c|}{$p$ for interaction } \\
\hline & & & & & & & \multirow{2}{*}{$\begin{array}{c}\text { Mild } \\
\text { SDB } \times \text { Sex }\end{array}$} & \multirow{2}{*}{$\begin{array}{l}\text { Moderate-to-severe } \\
\qquad \mathrm{SDB} \times \mathrm{Sex}\end{array}$} \\
\hline & 0 to $<5$ & 5 to $<15$ & $\geq 15$ & 0 to $<5$ & 5 to $<15$ & $\geq 15$ & & \\
\hline No. at risk & 1,031 & 527 & 152 & 2,358 & 473 & 65 & & \\
\hline \multicolumn{9}{|l|}{ Overweight } \\
\hline No. of cases (\%) & $234(23)$ & $256(49)$ & $97(64)$ & $507(22)$ & $234(49)$ & $42(65)$ & & \\
\hline Age-adjusted OR & 1.0 & $3.2(2.6,4.1)$ & $6.1(4.3,8.8)$ & 1.0 & $3.5(2.8,4.3)$ & $6.5(3.8,10.9)$ & & \\
\hline Multivariable-adjusted OR & 1.0 & $3.3(2.6,4.1)$ & $6.1(4.2,8.8)$ & 1.0 & $3.5(2.9,4.4)$ & $7.2(4.2,12.1)$ & 0.46 & 0.63 \\
\hline \multicolumn{9}{|l|}{ High blood pressure } \\
\hline No. of cases (\%) & $625(61)$ & $378(72)$ & $125(82)$ & $1,033(44)$ & $284(60)$ & $52(80)$ & & \\
\hline Age-adjusted OR & 1.0 & $1.6(1.3,2.0)$ & $2.8(1.8,4.3)$ & 1.0 & $1.5(1.2,1.9)$ & $3.9(2.1,7.3)$ & & \\
\hline Multivariable-adjusted OR & 1.0 & $1.5(1.2,1.9)$ & $2.6(1.6,4.0)$ & 1.0 & $1.5(1.2,1.9)$ & $4.0(2.1,7.5)$ & 0.84 & 0.33 \\
\hline Further adjustment for BMI & 1.0 & $1.2(1.9,1.5)$ & $1.7(1.0,2.6)$ & 1.0 & $1.1(0.8,1.4)$ & $2.2(1.1,4.2)$ & & \\
\hline \multicolumn{9}{|l|}{ Glucose abnormality } \\
\hline No. of cases (\%) & $202(20)$ & $96(18)$ & $46(30)$ & $197(8)$ & $63(13)$ & $13(20)$ & & \\
\hline Age-adjusted OR & 1.0 & $0.9(0.7,1.2)$ & $1.7(1.2,2.5)$ & 1.0 & $1.4(1.0,1.9)$ & $2.1(1.1,3.9)$ & & \\
\hline Multivariable-adjusted OR & 1.0 & $0.9(0.7,1.2)$ & $1.7(1.2,2.6)$ & 1.0 & $1.5(1.1,2.1)$ & $1.9(1.0,3.7)$ & 0.009 & 0.78 \\
\hline Further adjustment for BMI & 1.0 & $0.9(0.7,1.2)$ & $1.7(1.1,2.5)$ & 1.0 & $1.2(0.9,1.6)$ & $1.2(0.6,2.3)$ & & \\
\hline \multicolumn{9}{|l|}{ Low HDL cholesterol } \\
\hline No. of cases (\%) & $110(11)$ & $64(12)$ & $18(12)$ & $394(17)$ & $126(27)$ & $17(26)$ & & \\
\hline Age-adjusted OR & 1.0 & $1.3(0.8,1.6)$ & $1.1(0.6,1.8)$ & 1.0 & $1.7(1.3,2.1)$ & $1.5(0.9,2.7)$ & & \\
\hline Multivariable-adjusted OR & 1.0 & $1.3(0.9,1.8)$ & $1.3(0.8,2.2)$ & 1.0 & $1.7(1.3,2.2)$ & $1.2(0.6,2.3)$ & 0.28 & 0.70 \\
\hline Further adjustment for BMI & 1.0 & $1.2(0.8,1.6)$ & $1.1(0.6,2.0)$ & 1.0 & $1.3(1.0,1.7)$ & $1.0(0.6,1.9)$ & & \\
\hline \multicolumn{9}{|l|}{ High triglyceride } \\
\hline No. of cases (\%) & $294(29)$ & $197(37)$ & $60(39)$ & $363(15)$ & $110(23)$ & $28(43)$ & & \\
\hline Age-adjusted OR & 1.0 & $1.5(1.2,1.9)$ & $1.8(1.2,2.5)$ & 1.0 & $1.5(1.2,1.9)$ & $3.6(2.2,6.1)$ & & \\
\hline Multivariable-adjusted OR & 1.0 & $1.6(1.3,2.1)$ & $1.8(1.3,2.6)$ & 1.0 & $1.5(1.1,1.9)$ & $3.8(2.3,6.5)$ & 0.64 & 0.02 \\
\hline Further adjustment for BMI & 1.0 & $1.1(0.9,1.5)$ & $1.1(0.7,1.5)$ & 1.0 & $1.1(0.9,1.4)$ & $2.3(1.3,4.0)$ & & \\
\hline \multicolumn{9}{|l|}{ Metabolic syndrome } \\
\hline No. of cases $(\%)$ & $178(17)$ & $145(28)$ & $61(40)$ & $243(10)$ & $121(26)$ & $28(43)$ & & \\
\hline Age-adjusted OR & 1.0 & $1.8(1.6,2.3)$ & $3.2(2.2,4.6)$ & 1.0 & $2.6(2.0,3.4)$ & $5.5(3.3,9.3)$ & & \\
\hline Multivariable-adjusted OR & 1.0 & $1.9(1.6,2.4)$ & $3.2(2.2,4.7)$ & 1.0 & $2.6(2.1,3.4)$ & $5.8(3.4,9.8)$ & 0.03 & 0.04 \\
\hline
\end{tabular}

Multivariable-adjusted OR was adjusted for age (year), smoking status (nonsmoker and current smoker), current ethanol intake (g/day), time since last meal $(<2,2,3-7$ and $\geq 8$ hours) and for women, menopausal status (pre- and post-menopause).

$\mathrm{MetS}^{7-10)}$ as well as obesity, hypertension, glucose abnormality and high triglyceride levels ${ }^{2}$. Our results generally confirmed these previous findings.

OSA and MetS were each associated strongly with BMI. Then, we examined the association between the severity of nocturnal intermittent hypoxia and each metabolic risk factor after stratification by overweight status. The associations with high blood pressure, a high triglyceride level and the presence of two or more metabolic risk factors were modified by overweight and BMI. To our knowledge, this study is the first to show significant interaction between nocturnal intermittent hypoxia and BMI in relation to metabolic risk factors.

Several mechanisms, other than being overweight, for nocturnal intermittent hypoxia affect metabolic risk factors. First, reduced blood oxygen saturation stimulates peripheral arterial chemoreceptors, especially carotid bodies, and enhances sympathetic drive, an effect which appears to be carried over into normal waking hours, leading to elevated blood pressure $^{21)}$. This mechanism was supported by reports that nasal continuous positive pressure reduced baroreceptor sensitivity ${ }^{22)}$ and ambulatory blood pressure ${ }^{23)}$. Second, increased sympathetic tone also raised serum catecholamine levels, leading to elevated serum glu- 
Table 3. Age, sex- and multivariable-adjusted odds ratios ( $95 \%$ confidence intervals) of metabolic risk factors and the presence of $\geq 2$ metabolic risk factors according to the $3 \%$ oxygen desaturation index, stratified by overweight

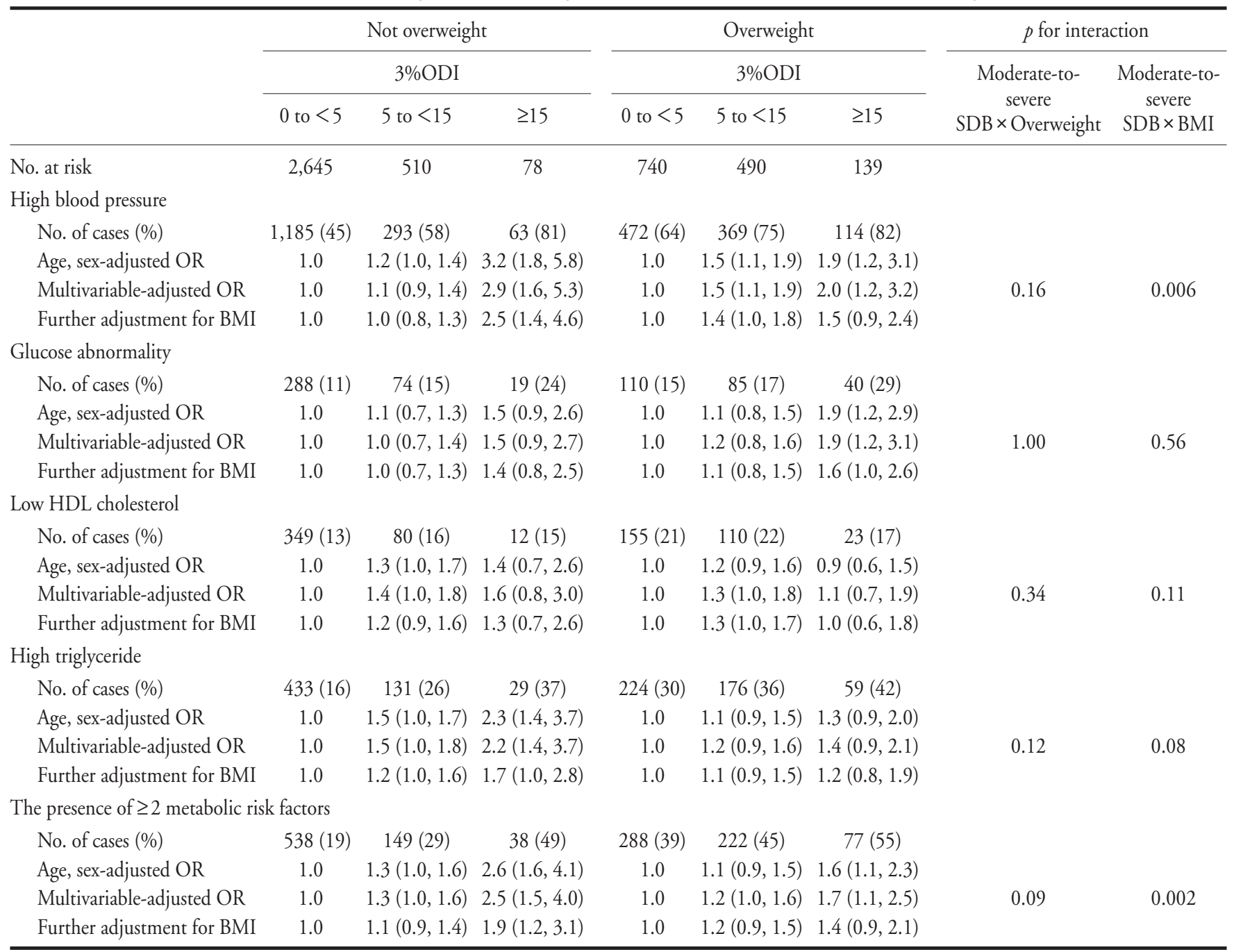

Multivariable-adjusted OR was adjusted for age (year), sex, body mass index $\left(\mathrm{kg} / \mathrm{m}^{2}\right)$, smoking status (nonsmoker and current smoker), current ethanol intake (g/day), time since last meal $(<2,2,3-7$ and $\geq 8$ hours) and for women, menopausal status (pre- and post-menopause).

cose levels ${ }^{24)}$. Third, oxidative stress owing to repetitive hypoxia elevated cytokine levels (e.g. tumor necrosis factor- $\alpha$; TNF- $\alpha$ and interleukin-6; IL-6) ${ }^{25}$, which led to increased insulin resistance ${ }^{26}$. Fourth, sleep deprivation and the stress there from inhibited slow wave sleep and activated the hypothalamic-pituitaryadrenal axis ${ }^{27)}$. Inhibition of slow wave sleep decreased growth hormone levels, leading to a reduction in metabolism, and serum leptin levels and increased serum grhelin levels, leading to the stimulation of appetite. Activation of the hypothalamic-pituitaryadrenal axis increased serum cortisol levels ${ }^{28)}$, leading to hyperglycemia and insulin resistance ${ }^{29)}$. Lastly, an experimental study has shown that intermittent hypoxia caused an increase in hepatic levels of triglyceride and phospholipid, and upregulated the expression of genes involved in lipid biosynthesis in mice ${ }^{30}$. Therefore, nocturnal intermittent hypoxia may increase serum triglyceride levels.

To explain the interaction between nocturnal intermittent hypoxia and BMI in relation to high blood pressure and high triglyceride levels, we considered whether BMI affects metabolic risk factors both directly and indirectly. Being overweight is associated with the accumulation of fat, which increases levels of free fatty acids and adipokines (e.g. TNF- $\alpha$ and IL-6) ${ }^{31,32)}$. An increase in adipokines causes elevated blood pressure ${ }^{33)}$. An increase in free fatty acids causes 
lipoprotein synthesis in the liver and raises serum triglyceride levels ${ }^{34)}$. Being overweight may also be associated with metabolic risk factors indirectly, mediated by nocturnal intermittent hypoxia. For example, reduced oxygen saturation enhances sympathetic activity to raise blood pressure ${ }^{23)}$ and the production of VLDL in liver, and raises blood triglyceride levels ${ }^{30)}$, common pathways in overweight individuals. Therefore, being overweight may weaken the effect of nocturnal intermittent hypoxia on high blood pressure and high triglyceride levels.

The strengths of the present study were the large sample size $(n \approx 4,000)$, and community-based approach. Another strength was that we investigated lean persons in Asia, whereas previous large studies were mainly of obese or overweight persons in the United States.

Several limitations of the present study need to be discussed. First, the study had a cross-sectional design. Therefore, we cannot prove the causality between nocturnal intermittent hypoxia and MetS. Second, we measured oxygen desaturation during sleep by pulse-oximetry to estimate OSA. Since apneic episodes do not always cause oxygen desaturation, we could not accurately estimate very mild OSA. However, the specificity of the screening remained high ${ }^{20)}$. Third, we used BMI as the definition of MetS. Some studies reported that abdominal obesity had a stronger association with OSA than did high $\mathrm{BMI}^{35}$. Therefore, there may be some, though not substantial, misclassification because a previous study reported that BMI was highly correlated with abdominal fat as well as waist circumference $(r=0.87$ for BMI and $r=0.91$ for waist circumference) ${ }^{36)}$. Fourth, the same cutoff point of serum triglycerides was used for fasting and non-fasting data as the criterium for high triglyceride levels. Although justification of the use of the same cutoff point as fasting status is under debate, the data of non-fasting triglycerides can be used because it is a significant predictor for ischemic heart disease ${ }^{14)}$. Fifth, we used a non-fasting glucose concentration $\geq 140 \mathrm{mg} / \mathrm{dL}(7.77 \mathrm{mmol} / \mathrm{L})$ as a component of MetS. Although we defined fasting status as more than 8 hours after the last meal, plasma glucose levels returned to pre-prandial levels in 2-3 hours after the last meal among subjects with normal glucose tolerance ${ }^{37)}$. The proportion of participants with glucose abnormality for each definition of fasting status (more than 8 hours after the last meal vs. more than 3 hours after the last meal) was $14 \%$ vs. $25 \%$ for non-fasting and $26 \%$ vs. $24 \%$ for fasting in men, and in women, $14 \%$ vs. $11 \%$ and $12 \%$ vs. $12 \%$, respectively. Therefore, we may have underestimated the number of participants with glucose abnormality among men. However, there was no difference change in our results between definitions of fasting status.

Mean BMI is much lower in $\mathrm{Asia}^{38)}$, and the prevalence of OSA was reported to be less than half that in the United States ${ }^{39)}$. However, our findings suggest that OSA affects cardiovascular risk factors more strongly among lower BMI populations. Therefore, the impact of OSA on cardiovascular risk factors may be potentially large in Asia.

\section{Acknowledgements}

We thank Dr. Mitsumasa Umesawa, MD, PhD, Ms. Yukiko Ichikawa and Ms. Miyuki Notsute for technical assistance, and Ms. Minako Kudo, Ms. Kazuyo Kamei and staff of the Osaka Medical Center for Health Science and Promotion, Osaka University and the University of Tsukuba for data collection.

\section{Notice of Grant Support}

This was not an industry supported study. This study was supported in part by grants from the Japanese Ministry of Education, Culture, Sports, Science and Technology (Grant-in-Aid for research B: 14370132) and the Health and Labor Sciences Research Grant (Clinical Research for Evidence Based Medicine), Ministry of Health, Welfare and Labor, the FULLHAP, Japan, and the University Research Project Research Grant (B), University of Tsukuba. Drs. Muraki, Tanigawa, Yamagishi, Sakurai, Cui, Imano, Sato, Kitamura, Shimamoto, Konishi and Iso have indicated no conflicts of interest.

\section{References}

1) Caples SM, Garcia-Touchard A, Somers VK: Sleep-disordered breathing and cardiovascular risk. Sleep, 2007; 30: 291-303

2) Young T, Peppard PE, Gottlieb DJ: Epidemiology of obstructive sleep apnea: a population health perspective. Am J Respir Crit Care Med, 2002; 165: 1217-1239

3) Somers VK, White DP, Amin R, Abraham WT, Costa F, Culebras A, Daniels S, Floras JS, Hunt CE, Olson LJ, Pickering TG, Russell R, Woo M, Young T: Sleep apnea and cardiovascular disease: an American Heart Association/ American College of Cardiology Foundation Scientific Statement from the American Heart Association Council for High Blood Pressure Research Professional Education Committee, Council on Clinical Cardiology, Stroke Council, and Council on Cardiovascular Nursing. J Am Coll Cardiol, 2008; 52: 686-717

4) Teramoto T, Sasaki J, Ueshima H, Egusa G, Kinoshita M, Shimamoto K, Daida H, Biro S, Hirobe K, Funahashi T, 
Yokote K, Yokode M: Metabolic syndrome. J Atheroscler Thromb, 2008; 15: 1-5

5) Teramura M, Emoto M, Araki T, Yokoyama H, Motoyama K, Shinohara K, Mori K, Koyama H, Shoji T, Inaba M, Nishizawa Y: Clinical impact of metabolic syndrome by modified NCEP-ATPIII criteria on carotid atherosclerosis in Japanese adults. J Atheroscler Thromb, 2007; 14: 172178

6) Iso H, Sato S, Kitamura A, Imano H, Kiyama M, Yamagishi K, Cui R, Tanigawa T, Shimamoto T: Metabolic syndrome and the risk of ischemic heart disease and stroke among Japanese men and women. Stroke, 2007; 38: 17441751

7) Lam JC, Lam B, Lam CL, Fong D, Wang JK, Tse HF, Lam KS, Ip MS: Obstructive sleep apnea and the metabolic syndrome in community-based Chinese adults in Hong Kong. Respir Med, 2006; 100: 980-987

8) Parish JM, Adam T, Facchiano L: Relationship of metabolic syndrome and obstructive sleep apnea. J Clin Sleep Med, 2007; 3: 467-472

9) Sasanabe R, Banno K, Otake K, Hasegawa R, Usui K, Morita M, Shiomi T: Metabolic syndrome in Japanese patients with obstructive sleep apnea syndrome. Hypertens Res, 2006; 29: 315-322

10) Coughlin SR, Mawdsley L, Mugarza JA, Calverley PM, Wilding JP: Obstructive sleep apnoea is independently associated with an increased prevalence of metabolic syndrome. Eur Heart J, 2004; 25: 735-741

11) Vgontzas AN, Papanicolaou DA, Bixler EO, Hopper K, Lotsikas A, Lin HM, Kales A, Chrousos GP: Sleep apnea and daytime sleepiness and fatigue: relation to visceral obesity, insulin resistance, and hypercytokinemia. J Clin Endocrinol Metab, 2000; 85: 1151-1158

12) Vgontzas AN, Bixler EO, Chrousos GP: Sleep apnea is a manifestation of the metabolic syndrome. Sleep Med Rev, 2005; 9: 211-224

13) Imano H, Kitamura $A$, Sato $S$, Kiyama M, Ohira T, Yamagishi K, Noda H, Tanigawa T, Iso H, Shimamoto T: Trends for blood pressure and its contribution to stroke incidence in the middle-aged Japanese population: the Circulatory Risk in Communities Study (CIRCS). Stroke, 2009; 40: 1571-1577

14) Iso $H$, Naito $Y$, Sato $S$, Kitamura $A$, Okamura T, Sankai T, Shimamoto T, Iida M, Komachi Y: Serum triglycerides and risk of coronary heart disease among Japanese men and women. Am J Epidemiol, 2001; 153: 490-499

15) Tanigawa T, Tachibana N, Yamagishi K, Muraki I, Umesawa $M$, Shimamoto T, Iso $H$ : Usual alcohol consumption and arterial oxygen desaturation during sleep. JAMA, 2004; 292: 923-925

16) Nakamura M, Sato $S$, Shimamoto $T$ : Improvement in Japanese clinical laboratory measurements of total cholesterol and HDL-cholesterol by the US cholesterol reference method laboratory network. J Atheroscler Thromb, 2003; 10: 145-153

17) National Cholesterol Education Program (NCEP) Expert Panel on Detection, Evaluation, and Treatment of High Blood Cholesterol in Adults (Adult Treatment Panel III). Third Report of the National Cholesterol Education Program (NCEP) Expert Panel on Detection, Evaluation, and Treatment of High Blood Cholesterol in Adults (Adult Treatment Panel III) final report. Circulation, 2002; 106: 3143-3421

18) World Health Organization Western Pacific Region, International Association for the Study of Obesity and the International Obesity Task Force. The Asia-Pacific perspective: Redefining obesity and its treatment. Health Communications Australia Pty Limited: Australia; 2000

19) Clark JS, Votteri B, Ariagno RL, Cheung P, Eichhorn JH, Fallat RJ, Lee SE, Newth CJ, Rotman H, Sue DY: Noninvasive assessment of blood gases. Am Rev Respir Dis 1992; 145: 220-232

20) Nakamata M, Kubota Y, Sakai K, Kinebuchi S, Nakayama S, Ohira T, Sato S, Shinoda S, Kawano S: The limitation of screening test for patients with sleep apnea syndrome using pulse oximetry. J Jpn Soc Respir Care, 2003; 12: 401-406 (in Japanese)

21) Narkiewicz K, van de Borne PJ, Montano N, Dyken ME, Phillips BG, Somers VK: Contribution of tonic chemoreflex activation to sympathetic activity and blood pressure in patients with obstructive sleep apnea. Circulation, 1998; 97: 943-945

22) Coughlin SR, Mawdsley L, Mugarza JA, Wilding JP, Calverley PM: Cardiovascular and metabolic effects of CPAP in obese males with OSA. Eur Respir J, 2007; 29: 720-727

23) Pepperell JC, Ramdassingh-Dow S, Crosthwaite N, Mullins R, Jenkinson C, Stradling JR, Davies RJ: Ambulatory blood pressure after therapeutic and subtherapeutic nasal continuous positive airway pressure for obstructive sleep apnoea: a randomised parallel trial. Lancet, 2002; 359: 204-210

24) Nonogaki K: New insights into sympathetic regulation of glucose and fat metabolism. Diabetologia, 2000; 43: 533549

25) Ciftci TU, Kokturk O, Bukan N, Bilgihan A: The relationship between serum cytokine levels with obesity and obstructive sleep apnea syndrome. Cytokine, 2004; 28: $87-91$

26) Uysal KT, Wiesbrock SM, Marino MW, Hotamisligil GS: Protection from obesity-induced insulin resistance in mice lacking TNF-alpha function. Nature, 1997; 389: 610-614

27) Van Cauter E, Spiegel K, Tasali E, Leproult R: Metabolic consequences of sleep and sleep loss. Sleep Med, 2008; 9 Suppl 1: S23-S28

28) Spiegel K, Leproult R, Van Cauter CE: Impact of sleep debt on metabolic and endocrine function. Lancet, 1999; 354: 1435-1439

29) Follenius M, Brandenberger G, Bandesapt JJ, Libert JP, Ehrhart J: Nocturnal cortisol release in relation to sleep structure. Sleep, 1992; 15: 21-27

30) Li J, Nanayakkara A, Jun J, Savransky V, Polotsky VY: Effect of deficiency in SREBP cleavage-activating protein on lipid metabolism during intermittent hypoxia. Physiol Genomics, 2007; 31: 273-280

31) Chudek J, Wiecek A: Adipose tissue, inflammation and endothelial dysfunction. Pharmacol Rep, 2006; 58 Suppl: 81-88

32) Zimmermann R, Strauss JG, Haemmerle G, Schoiswohl G, Birner-Gruenberger R, Riederer M, Lass A, Neuberger G, Eisenhaber F, Hermetter A, Zechner R: Fat mobiliza- 
tion in adipose tissue is promoted by adipose triglyceride lipase. Science, 2004; 306: 1383-1386

33) Guzik TJ, Mangalat D, Korbut R: Adipocytokines - novel link between inflammation and vascular function? J Physiol Pharmacol, 2006; 57: 505-528

34) Jensen MD, Haymond MW, Rizza RA, Cryer PE, Miles JM: Influence of body fat distribution on free fatty acid metabolism in obesity. J Clin Invest, 1989; 83: 1168-1173

35) Vgontzas AN, Papanicolaou DA, Bixler EO, Hopper K, Lotsikas A, Lin HM, Kales A, Chrousos GP: Sleep apnea and daytime sleepiness and fatigue: relation to visceral obesity, insulin resistance, and hypercytokinemia. J Clin Endocrinol Metab, 2000; 85: 1151-1158

36) Hwang MJ, Chung WS, Gallagher D, Kim DY, Shin $\mathrm{HD}$, Song MY: How useful is waist circumference for assessment of abdominal obesity in Korean pre-menopausal women during weight loss? Asia Pac J Clin Nutr, 2008; 17: 229-234

37) American Diabetes Association. Postprandial blood glucose. American Diabetes Association. Diabetes Care, 2001; 24: 775-778

38) Balkau B, Deanfield JE, Després JP, Bassand JP, Fox KA, Smith SC Jr, Barter P, Tan CE, Van Gaal L, Wittchen HU, Massien C, Haffner SM: International Day for the Evaluation of Abdominal Obesity (IDEA): a study of waist circumference, cardiovascular disease, and diabetes mellitus in 168,000 primary care patients in 63 countries. Circulation, 2007; 116: 1942-1951

39) Lam B, Lam DC, Ip MS: Obstructive sleep apnoea in Asia. Int J Tuberc Lung Dis, 2007; 11: 2-11 